\title{
A glassy carbon electrode modified with reduced graphene oxide for sensitive determination of bumetanide in urine at levels required for doping analysis
}

\author{
Felipe Fantinato Hudari ${ }^{1}$ Maria Valnice Boldrin Zanoni ${ }^{1}$
}

Received: 7 April 2017 / Accepted: 1 August 2017 / Published online: 14 August 2017

(C) Springer-Verlag GmbH Austria 2017

\begin{abstract}
The dopant bumetanide (BMT) was banned by the World Anti-Doping Agency. The authors describe a voltammetric sensor for the determination of BMT in urine that is based on the use of a glassy carbon electrode modified with reduced graphene oxide (GCE/rGO). The GCE/rGO was prepared by electrodeposition from a solution of GO. The oxidation of BMT occurs best at $+0.75 \mathrm{~V}$ in the GCE/rGO with an approximately 13 -fold gain in the anode current compared to a conventional GCE. The oxidation mechanism was investigated by means of electrolysis, while the analysis of the products was carried out via the LC-MS/MS. Under optimized conditions (scan rate $100 \mathrm{mV} \mathrm{s}^{-1} ; \mathrm{pH} 4.0$; accumulation time $25 \mathrm{~s}$ ) and by using linear sweep adsorptive stripping voltammetry, the response covers the 0.26 to $50 \mu \mathrm{mol} \mathrm{L}{ }^{-1}$ BMT concentration range. The detection limit is $75 \mathrm{nmol}$ $\mathrm{L}^{-1}$. The sensor was successfully applied and validated by LC-MS/MS analysis of spiked urine sample.
\end{abstract}

Keywords Voltammetric sensor · Stripping voltammetry · Bumetanide $\cdot$ Doping $\cdot$ Urine sample $\cdot$ Diuretics

Electronic supplementary material The online version of this article (doi:10.1007/s00604-017-2443-5) contains supplementary material, which is available to authorized users.

Felipe Fantinato Hudari

felipe_fhudari@hotmail.com

1 Universidade Estadual Paulista (Unesp), Instituto de Química, Araraquara, Av. Prof. Francisco Degni, 55,

Araraquara, SP 14800-060, Brazil

\section{Introduction}

Bumetanide [3-(butylamino)-4-phenoxy-5-sulfamoylbenzoic], (BMT), is considered an effectively potent diuretic of the sulfamyl category $[1,2]$ presenting short yet quick action. As a result, this substance is widely used by competitive athletes in order to increase their urine flow, reduce weight and eliminate other possible evidence of illicit substances in their urine [3, 4]. Since 2004, the World Anti-Doping Agency (WADA) has been publishing a list of prohibited substances used by athletes with the aim of increasing their performance [5, 6]. At present, the WADA Code serves as an umbrella institution to more than 660 organizations including the International Olympic Committee and the International Football Federation (FIFA). The nature of its activities requires the services of accredited laboratories. In order to guarantee the principles of fair competition they need established accurate and sensitive analytical methods. Besides the rigid control of stimulants, narcotics, anabolic agents, $\beta$-blockers, glucocorticosteroids peptide hormone and others, the use of diuretics has been limited to a maximum of $250 \mathrm{ng} \mathrm{mL}^{-1}$ in urine [7]. Thus, there is a need for analytical methods capable of determining and quantifying diuretics in biological fluids.

The main methods known in the literature for BMT analysis include spectrophotometry [8], capillary zone electrophoresis [9], flow injection technique with fluorimetric detection [1] and HPLC methods coupled to mass spectrometry [10]. While these techniques have particular relevance when it comes to the analysis of BMT in complex biological matrices, they commonly exhibit undesirable analysis characteristics [11]. The electroanalytical sensors capable of improving signal and regardless of the need for sample preparation [12] are also demonstrated using copper (II) phthalocyanine complex in the quest for the determination of BMT. The authors indicated that the complex promotes electrocatalysis of BMT 
reaching a limit of quantification of $9.0 \times 10^{-7} \mathrm{~mol} \mathrm{~L}^{-1}$ [13]. Nevertheless, the most of these studies have limited linear region and higher detection limit than required for determination of BMT in urine.

Graphene - a flat thin sheet of carbon atoms having $\mathrm{sp}^{2}$ bonds, has attracted great interest in the development of electrochemical sensors due to its large surface area, excellent electrical conductivity, high capacitance and versatility [14, 15]. Particularly, the reduced graphene oxide ( $\mathrm{rGO}$ ) form has been widely applied in sensors owing to its higher conductivity compared to graphene oxide (GO) [16]. This form can be generated through chemical reduction reactions [16] and via electrochemical reduction [17] of graphene oxide. The strategy via electrochemical reduction has gained attention since it can be acquired directly in situ by electrodeposition [18] amplifying the performance while simplifying the construction process of the electroanalytical sensor.

The present work aims to explore the potential of the electrochemical reduction of graphene oxide in the modification of a glassy carbon electrode for the determination of BMT. The electrochemical oxidation mechanism was investigated and the products generated were identified by liquid chromatography with detection by mass spectrometry (LC-MS/MS). A voltammetric sensor was optimized via the testing of different parameters and the device was successfully applied for BMT determination in urine sample without any pretreatment at compatible levels required in doping analyses.

\section{Experimental}

\section{Reagents and equipments}

All chemicals used in this work were of analytical grade, and the solutions were prepared using ultra-pure water (Milli-Q® system, Millipore). Bumetanide (purity $\geq 98.0 \%$ ), graphene oxide $\left(4 \mathrm{mg} \mathrm{mL}^{-1}\right.$, dispersion in $\left.\mathrm{H}_{2} \mathrm{O}\right)$, potassium hexacyanoferrate (III), uric acid, glucose, urea, creatinine and potassium hexacyanoferrate (II) trihydrate were purchased from Sigma-Aldrich, Brazil (http://www. sigmaaldrich.com). Boric acid, phosphate acid, acetic acid and potassium chloride were from Merck, Brazil (http:// www.merck.com.br). Sodium hydroxide was purchased from Synth, Brazil (http://www.labsynth.com.br). Furosemide was purchased from Purifarma, Brazil (http:// www.purifarma.com.br). Standard solution of $0.01 \mathrm{~mol} \mathrm{~L}^{-1}$ of BMT was prepared in ethanol media which was diluted afterwards in Britton-Robinson buffer (B-R) of $0.10 \mathrm{~mol} \mathrm{~L}^{-}$ ${ }^{1}$ used as supporting electrolyte. The buffer was prepared by mixing appropriate amounts of $0.10 \mathrm{~mol} \mathrm{~L}^{-1}$ sodium hydroxide to orthophosphoric acid, acetic acid, and boric acid $\left(0.10 \mathrm{~mol} \mathrm{~L}^{-1}\right.$ in each) solution. Measurements of $\mathrm{pH}$ were carried out in a TECNOPON mPA $210 \mathrm{pH}$-meter while those involving scanning electron microscopy were made in a FEG-MEV pertaining to the JEOL $7500 \mathrm{~F}$ model. The electrochemical experiments (voltammetric techniques and electrochemical impedance spectroscopy) were carried out in an Autolab pgstat $302 \mathrm{~N}$ potentiostat equipped with a FRA32 AC module controlled by the NOVA software. LC-MS/MS analyses were performed in a High Performance Liquid Chromatography of 1200 Agilent Technologies coupled to a Mass Spectrometer 3200 QTRAP (Linear Ion Trap Quadrupole LC-ESI-MS/MS).

\section{Modification of the glassy carbon electrode}

A glassy carbon electrode (GCE) was manually polished with alumina paste of different particles sizes $(0.5,0.3$ and $0.05 \mu \mathrm{m}$ ) and washed with ultra-pure water (Milli-Q® system, Millipore). Standard solution of $4 \mathrm{mg} \mathrm{mL}^{-1}$ of GO was diluted 2 times with ultra-pure water and placed in ultrasonic bath for $4 \mathrm{~h}$. Afterwards, GO solution was diluted 1 time with $0.20 \mathrm{~mol}$ $\mathrm{L}^{-1}$ sodium sulfate solution (generating a suspension of $0.1 \mathrm{mg} \mathrm{mL}^{-1}$ of GO in $0.10 \mathrm{~mol} \mathrm{~L}^{-1}$ sodium sulfate solution). The electrodeposition of the graphene oxide solution previously prepared was carried out through the application of a potential of $-1.4 \mathrm{~V}$ during $500 \mathrm{~s}$ on the previously cleaned GCE [19]. Following modification, the glassy carbon electrode modified with reduced graphene oxide (GCE/rGO) was washed and maintained for $15 \mathrm{~min}$ at room temperature aiming at drying the film.

Modification with graphene oxide was prepared by dropping $10 \mu \mathrm{L}$ of the suspension prepared above $(0.1 \mathrm{mg}$ $\mathrm{mL}^{-1}$ of GO in $0.10 \mathrm{~mol} \mathrm{~L}^{-1}$ sodium sulfate solution) on the surface of the GCE and maintained at room temperature for drying and film formation $(4 \mathrm{~h})$.

\section{Electrochemical measurements}

All electrochemical measurements were carried out in an electrochemical cell of $10.0 \mathrm{~mL}$ with three-electrode system containing working (GCE e $\mathrm{GCE} / \mathrm{rGO}$ ), auxiliary (platinum wire), and reference $\left(\mathrm{Ag} \mid \mathrm{AgCl} ; \mathrm{KCl}, 3 \mathrm{~mol} \mathrm{~L}^{-1}\right)$ electrodes. After modification, the GCE/rGO was subjected to electrochemical cycling from 0.60 to $0.96 \mathrm{~V}$ in $0.10 \mathrm{~mol} \mathrm{~L}^{-1}$ buffer ( $\mathrm{pH}$ 4.0) for the electrode surface stabilization [20].

Electrochemical impedance spectroscopy (EIS) measurements were performed using $5 \mathrm{mmol} \mathrm{L}{ }^{-1} \mathrm{Fe}(\mathrm{CN})_{6}{ }^{3-14-}$ as redox probe $\left(0.1 \mathrm{~mol} \mathrm{~L}^{-1} \mathrm{KCl}\right)$, in the range of $10 \mathrm{kHz}-$ $0.03 \mathrm{~Hz}$, with a $5 \mathrm{mV}$ rms OCP sinusoidal modulation $(0.220 \mathrm{~V}$ vs $\mathrm{Ag} \mid \mathrm{AgCl})$.

The controlled potential electrolysis of the BMT diuretic was conducted in an electrochemical cell of $75.0 \mathrm{~mL}$ containing the working (vitreous carbon plate of $1.56 \mathrm{~cm}^{2}$ without and with modification by reduced graphene oxide), auxiliary (Ti/Ru sheet of $9 \mathrm{~cm}^{2}$ ), and reference $(\mathrm{Ag} \mid \mathrm{AgCl} ; \mathrm{KCl}, 3 \mathrm{~mol}$ 
$\mathrm{L}^{-1}$ ) electrodes in $0.10 \mathrm{~mol} \mathrm{~L}^{-1}$ buffer ( $\mathrm{pH} 4.0$ ) during $3 \mathrm{~h}$. For the curves of current vs time, a fixed potential of $0.96 \mathrm{~V}$ was applied so as to obtain the flat current.

\section{LC-MS/MS analysis}

The products of the electrolysis were identified by LC-MS/ MS equipped with a Phenomenex Kinetex PFP column $(150 \times 4.6 \mathrm{~mm} ; 5 \mu \mathrm{m})$. The mobile phase used for elution of the samples was a mixture of ultra-pure water containing $0.10 \%$ formic acid (A) and methanol (B) with a gradient programming of $0-2$ min $5 \% \mathrm{~B}, 2-12 \mathrm{~min} 5-100 \% \mathrm{~B}, 12-13 \mathrm{~min}$ $100 \% \mathrm{~B}, 13-14 \mathrm{~min} 100-5 \% \mathrm{~B}$, and $14-20 \mathrm{~min} 5 \% \mathrm{~B}$, using the flow rate of $1 \mathrm{~mL} \mathrm{~min}^{-1}$ and sample injection volume of $20 \mu \mathrm{L}[20]$.

The ion source was operated in an electrospray positive mode at $600{ }^{\circ} \mathrm{C}$ in the following conditions of ionization: ion spray voltage of $5500 \mathrm{~V}$; curtain gas of $20 \mathrm{psi}$; nebulizer gas $_{1}$ of $50 \mathrm{psi}$; nebulizer gas 2 of $50 \mathrm{psi}$; declustering potential $31 \mathrm{~V}$ and entrance potential of $10 \mathrm{~V} \mathrm{[20].}$

\section{Preparation and analysis of synthetic urine samples}

The synthetic urine sample was prepared as described in the following reference [21]. The synthetic urine sample was subsequently spiked with $6.86 \times 10^{-7} \mathrm{~mol} \mathrm{~L}^{-1}$ of BMT (equivalent to $250 \mathrm{ng} \mathrm{mL}^{-1}$ ). Then, $4 \mathrm{~mL}$ of synthetic urine samples was inserted without any previous treatment in an electrochemical cell containing $6 \mathrm{~mL}$ of buffer $(\mathrm{pH} 4.0)$ (equivalent to $100 \mathrm{ng} \mathrm{mL}^{-1}$ of BMT in the electrochemical cell).

\section{Analysis of human urine sample}

Human urine sample was collected from a healthy person who was volunteered. $10 \mathrm{~mL}$ of sample was spiked with $6.86 \times 10^{-7} \mathrm{~mol} \mathrm{~L}^{-1}$ of BMT (equivalent to $250 \mathrm{ng} \mathrm{mL}^{-1}$ ). Then, $4 \mathrm{~mL}$ of the sample was inserted without any prior treatment in an electrochemical cell containing $6 \mathrm{~mL}$ of buffer ( $\mathrm{pH} 4.0$ ) (equivalent to $100 \mathrm{ng} \mathrm{mL}^{-1}$ of BMT in the electrochemical cell).

For the analyses of urine samples via LC-MS/MS, a cleanup through a solid extraction process was employed. In a Phenomenex Strata-X 33u cartridge (200 mg, $3 \mathrm{~mL}$ ), previously conditioned with methanol $(3 \mathrm{~mL})$ and Milli-Q water (3 mL), $4 \mathrm{~mL}$ sample (equivalent to $6.86 \times 10^{-7} \mathrm{~mol} \mathrm{~L}^{-1}$ ) was added for extraction. After the sample loading, the sorbent was washed with $2 \mathrm{~mL}$ of Milli-Q water and dried for $1 \mathrm{~min}$ under nitrogen gas flow. Finally, the sample was eluted with $2 \mathrm{~mL}$ methanol and an aliquot $(150 \mu \mathrm{L}$ of sample $+150 \mu \mathrm{L}$ of Milli-Q water) was then inserted in vials for analysis by LCMS/MS.
The chromatographic analyses were performed with the same mobile phase described in section 2.4 though with the following gradient programming: $0-2 \min 30 \% \mathrm{~B}, 2-4 \mathrm{~min}$ $100 \% \mathrm{~B}, 4-5 \min 100 \% \mathrm{~B}, 5-6 \min 100-70 \% \mathrm{~B}$, and $6-$ $10 \min 70 \% \mathrm{~B}$.

\section{Results and discussion}

\section{Characteristics of the GCE/rGO}

Scanning electron microscopy (SEM) analyses show a clean, flawless surface for CGE (Fig. S1I). The GCE/GO presented an irregular shape with aspects of interconnected bulky blocks (Fig. S1II) [22, 23]. Following the electrochemical reduction of GO (Fig. S1III), a surface with large roughness is seen, where the pairing of several layers of graphene can be observed [24]. These characteristics are corroborated by spectroscopy measurements cited in literature [25-28]

The charge transfer kinetics for GCE, GCE/GO and GCE/ rGO were evaluated by electrochemical impedance spectroscopy (EIS) measurements using $5 \mathrm{mmol} \mathrm{L}^{-1}$ of $\mathrm{Fe}(\mathrm{CN})_{6}^{3-/ 4-}$ in $0.1 \mathrm{~mol} \mathrm{~L}^{-1}$ of $\mathrm{KCl}$. The value of charge transfer resistance $\left(\mathrm{R}_{\mathrm{ct}}\right)$ for GCE is equivalent to $265 \Omega$ (Fig. S2I). After modification of the GCE with GO film, there is an increase of $R_{c t}$ to $2.96 \mathrm{k} \Omega$ (Fig. S2II). This relative increase in the value of $\mathrm{R}_{\mathrm{ct}}$ can be attributed to the large amount of oxygen-containing group which tends to reduce the conductivity of the material as a result of the decrease of $\mathrm{sp}^{2}$ bonds between carbons $[22,29]$. The lowest value of $R_{c t}=62.6 \Omega$ was for $\mathrm{GCE} / \mathrm{rGO}$ (Fig. S2III), suggesting that restoration of the $\pi$-network occurs, leading to a rise in conductivity of the material [30].

\section{Electrochemical behavior of BMT on GCE/rGO}

Figure 1 compares the electrochemical behavior of $100 \mu \mathrm{mol}$ $\mathrm{L}^{-1}$ of BMT in $0.1 \mathrm{~mol} \mathrm{~L}^{-1}$ buffer ( $\mathrm{pH}$ 7.0) on GCE (a),

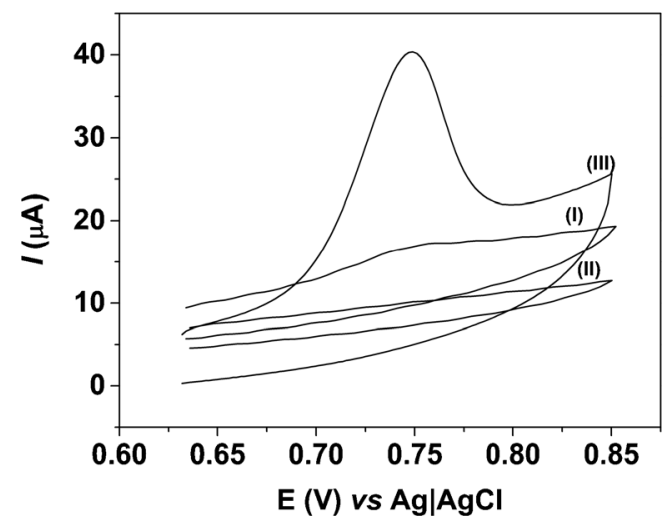

Fig. 1 Cyclic voltammograms for $100 \mu \mathrm{mol} \mathrm{L}^{-1}$ of BMT in $0.10 \mathrm{~mol} \mathrm{~L}^{-1}$ buffer (pH 7.0) on GCE (I), GCE/GO (II) and GCE/rGO (III). Scan rate of $100 \mathrm{mV} \mathrm{s}^{-1}$ 
GCE/GO (b) and GCE/rGO (c). BMT is oxidized at $0.75 \mathrm{~V}$ on GCE (Fig. 1I), featuring an irreversible process [31]. Already for the GCE/GO no peak was found (Fig. 1II). This confirms that the lowest conductivity of the GO film hinders BMT oxidation. However, while the BMT electrochemical behavior on the surface of $\mathrm{GCE} / \mathrm{rGO}$ is similar to the oxidation on the GCE, the peak intensity is found to be around 13 times higher when compared to unmodified electrode (Fig. 1III). This outcome is attributed to the higher conductivity and the increased electroactive area of the GCE/rGO (as shown in this section).

The effect of scan rate $(v)$ on the oxidation of $100 \mu \mathrm{mol} \mathrm{L}^{-1}$ of BMT in $0.1 \mathrm{~mol} \mathrm{~L}^{-1}$ buffer ( $\mathrm{pH} 7.0$ ) was investigated in the range of 2 to $100 \mathrm{mV} \mathrm{s}^{-1}$. A linear relationship was found through the following equation: $i_{\text {ap }}=3.96 \times 10^{-4} v+$ $1.30 \times 10^{-6}\left(\mathrm{R}^{2}=0.998\right)$, which led us to the conclusion that the charge transfer is controlled by adsorptive process [31].

Taking into consideration the Laviron equation for irreversible process controlled by analyte adsorption expressed as $\mathrm{E}_{a p}=\mathrm{E}^{0}-\left(\frac{R T}{\alpha n T}\right) \ln \left(\frac{R T}{\alpha n T}\right)+\left(\frac{R T}{\alpha n T}\right) \ln v[20,32]$, an estimation was made aiming at finding out the electrons involved in the process. From the slope of the relationship between $E_{\text {ap }}$ vs $\ln v$, which follows the equation: $E_{\mathrm{ap}}=0.0247 \ln v+0.799\left(R^{2}=\right.$ $0.994)$, the $\alpha n$ value was estimated. Substituting the values of R (8.314 $\left.\mathrm{J} \mathrm{mol}^{-1} \mathrm{k}^{-1}\right)$, T (298 K) and $\mathrm{F}\left(96,485 \mathrm{C} \mathrm{mol}^{-1}\right)$, the $\alpha n$ value is 1.04 . Considering the $\alpha$ value of around 0.5 [32], the value of $n$ is equal to 2.10, which indicates that BMT is oxidized after two electrons transfer process.

The active area of GCE and GCE/rGO was compared by cyclic voltammograms recorded for $1.00 \mathrm{mmol} \mathrm{L}^{-1}$ potassium hexacyanoferrate (III) solution as model compound in $0.1 \mathrm{~mol}$ $\mathrm{L}^{-1} \mathrm{KCl}$ solution (diffusion coefficient $=7.60 \times 10^{-6} \mathrm{~cm}^{2} \mathrm{~s}^{-1}$ ). By using the Randles-Sevcik equation [3 1 ] $\left(i_{a p}=2.69 \times 10^{5} n^{3 / 2} A D_{0}^{1 / 2} C_{0} v^{1 / 2}\right)$, the active area of GCE/rGO was found to be $0.233 \mathrm{~cm}^{2}$, which represents an increase of approximately 4 times as compared to the active area of the GCE $\left(0.0554 \mathrm{~cm}^{2}\right)$.

\section{Electrochemical oxidation mechanism of BMT}

In order to propose an electrochemical oxidation mechanism for BMT on $\mathrm{GCE} / \mathrm{rGO}$, further experiments were carried out using controlled potential electrolysis as described in section 2.3.

Upon the completion of the electrolysis on both GCE and $\mathrm{GCE} / \mathrm{rGO}$, the oxidation products were analyzed by $\mathrm{LC}-\mathrm{MS} / \mathrm{MS}$ as described in section 2.4. Figure 2I exhibits the total ion chromatogram (TIC) for the solution containing BMT prior to electrolysis (control solution), where it showed characteristic peak at retention time $\left(t_{\mathrm{rt}}\right)$ of $9.3 \mathrm{~min}$ with $\mathrm{m} / \mathrm{z}$ 365 , corresponding to the diuretic (MW. $364 \mathrm{Da},[\mathrm{M}+\mathrm{H}]^{+}$) (Fig. 2II).
After the diuretic electrolysis on GCE, the peak of the diuretic was observed at the same $t_{\mathrm{rt}}$. And $\mathrm{m} / \mathrm{z}$ along with two oxidation products which were detected by LC - MS/ MS. The product with the highest signal intensity was found at $t_{\mathrm{rt} \text {. }}$ of $10.4 \mathrm{~min}$ with $\mathrm{m} / \mathrm{z} 363\left([\mathrm{M}+\mathrm{H}]^{+}\right)$(Fig. 2III) (P1). The BMT fragment ion spectra (Fig. 2IV) showed $m / z, 346$ (loss of $17 \mathrm{Da},-\mathrm{NH}_{3}$ ), $\mathrm{m} / z 304$ (loss of $42 \mathrm{Da},-\mathrm{CH}_{2} \mathrm{CHCH}_{3}$ ) and $\mathrm{m} / \mathrm{z}$ 238 (loss of $108 \mathrm{Da},-\mathrm{SO}_{2}$ and $-\mathrm{CO}_{2}$ ).

The second product with lower signal intensity was observed at $t_{\mathrm{rt}} .8 .5 \mathrm{~min}$ with $\mathrm{m} / \mathrm{z} .381\left([\mathrm{M}+\mathrm{H}]^{+}\right)($Fig. $2 \mathrm{~V})$ (P2). The BMT fragment ion spectra (Fig. 2VI) showed $\mathrm{m} / \mathrm{z}$ 363 (loss of $18 \mathrm{Da},-\mathrm{H}_{2} 0$ ), $m / z 282$ (loss of $81 \mathrm{Da},-\mathrm{NH}_{3}$ and $-\mathrm{SO}_{2}$ ) and $m / z 254$ (loss of $28 \mathrm{Da},-\mathrm{CH}_{2} \mathrm{CH}_{2}$ ). All of the fragments mentioned are shown in Table $\mathrm{S} 1$.

Nonetheless, when BMT is electrolyzed at oxidation potential on GCE/rGO, beyond the peak of BMT at $9.3 \mathrm{~min}$ with $\mathrm{m} / \mathrm{z} 365$, only the product with $\mathrm{m} / \mathrm{z}, 381$ at $8.5 \mathrm{~min}$ was observed (P2) with the same fragments ions shown in Fig. 2VI.

Taking into account all the studies performed, we suggest the following electrochemical mechanism in Scheme 1 [33]. The secondary amine group in the BMT in aqueous solution on GCE is oxidized after two electrons transfer and loss of two protons, generating the product $\mathrm{P} 1$. The following hydroxyl group addition on $\mathrm{P} 1$ gives rise to $\mathrm{P} 2$ on GCE. Nevertheless, it is worth pointing out that the BMT oxidation process on $\mathrm{GCE} /$ rGO leads to the formation of only P2 product. This can be regarded as a proof reflecting the greater acceleration of the oxidation process which entails the immediate oxidation of $\mathrm{P} 1$ to $\mathrm{P} 2$, detected here only as final product of oxidation.

\section{Electroanalytical determination of BMT}

Guided by the goal of obtaining lower levels of BMT detection using the $\mathrm{GCE} / \mathrm{rGO}$ sensor the following parameters were optimized: (a) Sample pH value; (b) Electroanalytical method; (c) Accumulation time. Respective data and Figures (Fig. S3) are given in the Electronic Supporting Material. The following experimental conditions were found to give best results: (a) A sample $\mathrm{pH}$ value of 4.0 ; (b) linear sweep adsorptive stripping voltammetry (LSAdSV) as an electrochemical method; (c) $25 \mathrm{~s}$ as accumulation time.

The analytical performance of the method was tested using the above optimized conditions. An analytical curve was constructed in the range of 0.255 to $50.0 \mu \mathrm{mol} \mathrm{L}^{-1}$ of BMT (Fig. 3) and a linear relationship was found following equation $i_{\text {ap }}=1.68[\mathrm{BMT}]+5.39 \times 10^{-7}\left(\mathrm{R}^{2}=0.999\right)($ Insert of Fig. 3$)$. The limits of detection (LOD) and quantitation (LOQ) were calculated using the following equations: $\mathrm{LOD}=3 \mathrm{std} / \mathrm{m}$ and $\mathrm{LOQ}=10 \mathrm{std} / \mathrm{m}$, where $s t d$. is the standard deviation of 10 linear sweep adsorptive stripping (LSAdS) voltammograms with the supporting electrolyte only $\left(0.10 \mathrm{~mol} \mathrm{~L}^{-1}\right.$ buffer (pH 4.0) and $m$ being the slope of the curve. The values for LOD and LOQ were $75 \times 10^{-9} \mathrm{~mol} \mathrm{~L}^{-1}$ and $25 \times 10^{-8} \mathrm{~mol}$ 

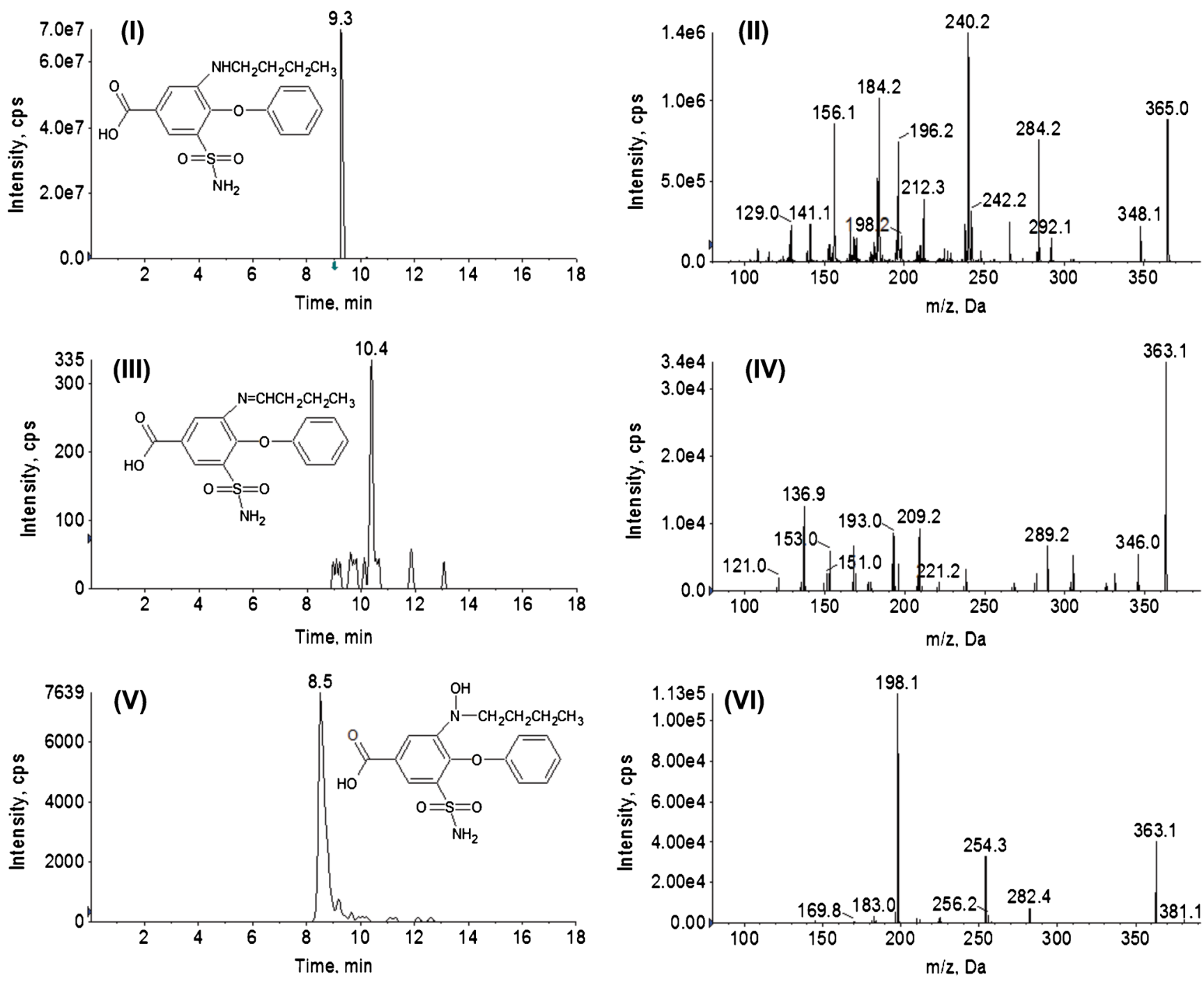

Fig. 2 I Total ion chromatogram (TIC) of control sample with $m / z, 365$. II Mass spectra of $9.3 \mathrm{~min}$ peak detected in (I). III Chromatogram of the product at $10.4 \mathrm{~min}$ with $\mathrm{m} / \mathrm{z} 363$. IV Mass spectra of product detected in

$\mathrm{L}^{-1}$, respectively. A comparison of the electroanalytical methods reported in the literature for the determination of BMT is summarized in Table 1. From these data, it is possible to conclude that our method presents better performance in relation to the linear response and detection limits in agreement with other voltammetric methods found in the literature $[13,34]$.

The intra-day repeatability was verified by 10 consecutive analyses for solutions containing concentrations of BMT of

(III). V Chromatogram of the product at $8.5 \mathrm{~min}$ with $\mathrm{m} / \mathrm{z}, 381$. VI Mass spectra of product detected in (V)

0.50 and $15.0 \mu \mathrm{mol} \mathrm{L}{ }^{-1}$, where the relative standard deviations (RSD) found were 3.40 and $2.70 \%$, respectively. The repeatability in 5 modifications was analyzed for the concentrations of 0.50 and $15.0 \mu \mathrm{mol} \mathrm{L}{ }^{-1}$ of BMT, where RSD among 5 modified electrodes were in the range of 0.80 to $4.0 \%$ and 0.30 to $1.8 \%$, respectively. These data indicate that the GCE/rGO does not undergo poisoning during the consecutive tests since the solution is stirred between measurements. Moreover, the sensor is seen to be robust as it presented low

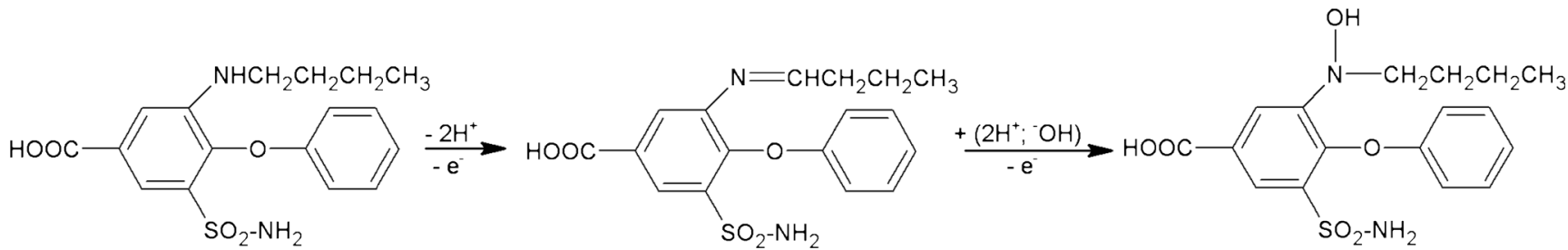

Scheme 1 Oxidation mechanism for BMT 


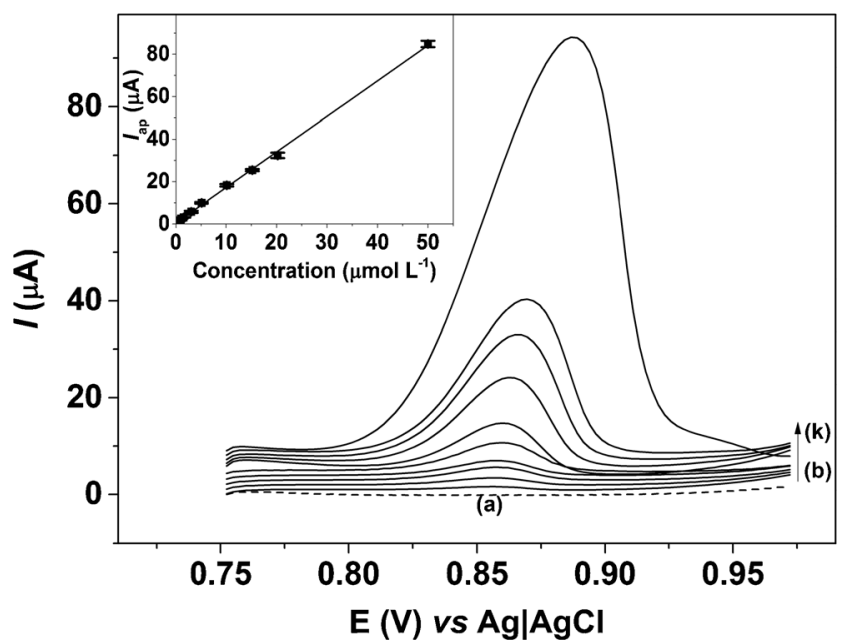

Fig. 3 Linear sweep adsorptive stripping voltammograms for $0.10 \mathrm{~mol}$ $\mathrm{L}^{-1}$ buffer ( $\left.\mathrm{pH} 4.0\right)(a)$ varying the concentration of BMT in 0.255 (b), $0.509(c), 1.01(d), 1.52(e), 3.02(f), 5.09(g), 10.2(h), 15.2(i), 20.2$ (j) and $50.0 \mu \mathrm{mol} \mathrm{L}{ }^{-1}(k) . v=100 \mathrm{mV} \mathrm{s}^{-1}$. Figure insert: Relation between $I_{\text {ap }}$ vs $[\mathrm{BMT}](n=3)$

values of RSD for intraday repeatability and among the modified electrodes.

\section{Interference study}

The $i_{\text {ap }}$ and resolution of the anodic peak of BMT was analyzed in the presence of possible interfering compounds such as uric acid (UA), creatinine (CR), glucose (GL), urea (UR) and furosemide (FUR). Under optimized conditions, LSAdS voltammograms were recorded for a solution containing $15.0 \mu \mathrm{mol} \mathrm{L} \mathrm{L}^{-1}$ of BMT and the possible interfering compounds in different concentrations comprising the range of 1.50 to $60 \mu \mathrm{mol} \mathrm{L}^{-1}$ (Fig. S4I). All the tested compounds at considered concentrations, except FUR, no exhibited anodic peak close to BMT, presented well-defined voltammetric peaks with a relatively good resolution of the diuretic. As can be seen in Fig. S4I, the percentages between the $i_{\text {ap }}$ of the BMT in the presence of compounds interfering $\left(i_{\text {inter. }}\right)$ on the $i_{\text {ap }}$ of the BMT ( $\left.i_{\mathrm{BMT}}\right)$ for UA $(\bullet), \mathrm{CR}(\mathbf{\bullet})$, GL (०) and UR ( $\square$ ) were in the range of 98.8-104, 95.6-102, 96.5-99.5 and $97.5-103 \%$, respectively. This indicates that these substances showed no interference in the $i_{\text {ap }}$ of BMT in the concentration range studied because they did not present a peak overlap. Testing furosemide as interfering $(\boldsymbol{\Lambda})$, an anodic peak was
Table 2 Determination of human urine sample by using the GCE/rGO method and LC-MS/MS technique

\begin{tabular}{lll}
\hline Method & GCE/rGO & LC-MS/MS \\
\hline Found values $\left(\times 10^{-7} \mathrm{~mol} \mathrm{~L}^{-1}\right)$ & $6.96 \pm 0.0488$ & $6.73 \pm 0.0113$ \\
\hline
\end{tabular}

$(n=3)$

observed at $+0.994 \mathrm{~V}$, as shown in Fig. S4II. However, for a FUR concentration up to 4 times higher (in the case $60 \mu \mathrm{mol}$ $\mathrm{L}^{-1}$ ) than BMT concentration, no interference in the $i_{\text {ap }}$ was observed, because the oxidation of furosemide is observed $80 \mathrm{mV}$ after BMT, enabling the determination of both, BMT and FUR, without interference in the studied concentrations. The relationship of percentages between the $i_{\text {ap }}$ of the BMT in the presence of FUR $\left(i_{\text {inter. }}\right)$ for the concentration range of 1.5 to $60 \mu \mathrm{mol} \mathrm{L}{ }^{-1}$ were between $96.2-100 \%$.

\section{Application of the method}

The performance of the GCE/rGO sensor was initially applied in tap water samples spiked with $15.0 \mu \mathrm{mol} \mathrm{L}^{-1}$ of BMT. The diuretic recoveries were in the range of 99.3 to $101 \%$, indicating that the error is inferior (or equal) to $1 \%$ (Table S2). In addition, the calculated value of $t\left(t_{\text {calc. }}\right)$ was found to be smaller compared to that of the tabulated $t\left(t_{\text {tab. }}\right)$, showing that there is no significant difference at $95 \%$ confidence interval between the fortified and recovered concentrations. These data indicate a relatively good applicability of the method.

The applicability of CGE/rGO was also tested in a synthetic urine sample previously prepared (section 2.5). Applying the standard addition method, the value found was 6.72 $( \pm 0.166) \times 10^{-7} \mathrm{~mol} \mathrm{~L}^{-1}$, which represents $97.9 \%$ of recovery.

The applicability of CGE/rGO was also tested in real human urine sample. The BMT concentration in the sample was found through the standard addition method and the results are shown in Table 2. For comparison, the method was compared with the LC-MS/MS technique. As can be seen in Table 2, the concentration of BMT found in the sample was similar in both methods. By computing the Students $t$ test (paired $t$-test), the value found was 0.511 , which is lower than the value of the tabulated $t$ (4.30) [35]. Thus, the results presented no significant difference at $95 \%$ confidence between the two methods.
Table 1 An overview on nanomaterial-based methods for determination of Bumetanide

\begin{tabular}{lllll}
\hline Electrode & Technique & Concentration range $\left(\mathrm{mol} \mathrm{L}^{-1}\right)$ & LOD $\left(\mathrm{mol} \mathrm{L}^{-1}\right)$ & Reference \\
\hline CPE & LSV & $2.74 \times 10^{-6}$ to $2.74 \times 10^{-5}$ & $4.39 \times 10^{-7}$ & {$[34]$} \\
CPE/complex CuPC & SWV & $9.90 \times 10^{-7}$ to $8.30 \times 10^{-6}$ & $2.70 \times 10^{-7}$ & {$[13]$} \\
GCE/rGO & LSAdSV & $2.55 \times 10^{-7}$ to $5.00 \times 10^{-5}$ & $7.50 \times 10^{-8}$ & This work \\
\hline
\end{tabular}

CPE: carbon paste electrode; CPE/complex CuPC: carbon paste electrode modified with copper(II) $1,2,3,4,8,9,10,11,15,16,17,18,22,23,24,25$-hexadecafluoro- $29 \mathrm{H}, 31 \mathrm{H}$-phthalocyanine 


\section{Conclusion}

The results of our present work indicate that glassy carbon electrode modified with reduced graphene oxide (GCE/rGO) can be a good alternative for determining BMT in urine sample at low levels. The modification of the electrode with a reduced graphene oxide ( $\mathrm{rGO}$ ) reduced the charge transfer resistance besides increasing drastically increase in the peak intensity of BMT compared to the GCE. The studies of controlled potential electrolysis indicated that the amine group is oxidized in the molecule and the final product identified by LC-MS-MS is found to be similarly on both GCE and GCE/ rGO. Interestingly, however, the intermediate of the reaction is not identified during the oxidation on modified electrode when compared to the GCE electrode, suggesting a rapid formation of the final product. The sensor was successfully employed in urine sample containing the allowable concentration level of BMT set out by WADA. The comparison was performed by the LC-MS/MS method. It is noteworthy that the results pointed out no significant difference between the two methods, indicating that the GCE/rGO sensor can be successfully applied in urine samples. Furthermore, the fact that this sensor presented lower detection limit and higher linear relationship compared with other works reported in the literature for the determination of BMT diuretic renders it a suitable alternative when it comes to such analyses.

Acknowledgements The authors would like to express their sincerest gratitude and indebtedness to the Brazilian funding agencies $\mathrm{CNPq}$ (grant numbers 153169/2014-1 and 446245/2014-3), FAPESP and CAPES for the financial support granted during the course of this research. Our thanks also go to LMA-IQ for providing the FEG-SEM facilities and to Brian Newmann - the native English language editor, for his painstaking proofreading and editing of the manuscript.

Compliance with ethical standards The author(s) declare that they have no competing interests.

\section{References}

1. Solich P, Polydorou CK, Koupparis MA, Efstathiou CE (2001) Automated flow injection fluorimetric determination and dissolution studies of bumetanide in pharmaceuticals. Anal Chim Acta 438:131-136. doi:10.1016/S0003-2670(01)00844-3

2. Patel DS, Sharma N, Patel MC et al (2012) Application of a rapid and sensitive liquid chromatography-tandem mass spectrometry method for determination of bumetanide in human plasma for a bioequivalence study. J Pharm Biomed Anal 66:365-370. doi:10. 1016/j.jpba.2012.03.018

3. Goebel C, Trout GJ, Kazlauskas R (2004) Rapid screening method for diuretics in doping control using automated solid phase extraction and liquid chromatography-electrospray tandem mass spectrometry. Anal Chim Acta 502:65-74. doi:10.1016/j.aca.2003.09.062

4. Deventer K, Pozo OJ, Van EP et al (2009) Qualitative detection of diuretics and acidic metabolites of other doping agents in human urine by high-performance liquid chromatography-tandem mass spectrometry: comparison between liquid-liquid extraction and direct injection. J Chromatogr A 1216:5819-5827. doi:10.1016/j. chroma.2009.06.003

5. Yadav SK, Chandra P, Goyal RN, Shim Y-B (2013) A review on determination of steroids in biological samples exploiting nanobioelectroanalytical methods. Anal Chim Acta 762:14-24. doi:10. 1016/j.aca.2012.11.037

6. Prohibited Substances $\mid$ List of Prohibited Substances and Methods. http://list.wada-ama.org/prohibited-all-times/prohibitedsubstances/. Accessed 9 Mar 2016

7. Deventer K, Pozo OJJ, Van EP et al (2009) Detection of urinary markers for thiazide diuretics after oral administration of hydrochlorothiazide and altizide-relevance to doping control analysis. J Chromatogr A 1216:2466-2473. doi:10.1016/j.chroma.2009.01.032

8. Sastry CSP, Prasad TNV, Sastry BS, Rao EV (1988) Spectrophotometric methods for the determination of some diuretics using 3-methyl-2-benzothiazolinone hydrazone. Analyst 113:255. doi:10.1039/an9881300255

9. González E, Becerra A, Laserna JJ (1996) Direct determination of diuretic drugs in urine by capillary zone electrophoresis using fluorescence detection. J Chromatogr B Biomed Sci Appl 687:145150. doi:10.1016/S0378-4347(96)00100-4

10. Mahshid S, Li C, Mahshid SS et al (2011) Sensitive determination of dopamine in the presence of uric acid and ascorbic acid using $\mathrm{TiO} 2$ nanotubes modified with $\mathrm{Pd}, \mathrm{Pt}$ and au nanoparticles. Analyst 136:2322-2329. doi:10.1039/c1an15021a

11. Hudari FF, de Almeida LC, da Silva BF, Zanoni MVB (2014) Voltammetric sensor for simultaneous determination of $\mathrm{p}$ phenylenediamine and resorcinol in permanent hair dyeing and tap water by composite carbon nanotubes/chitosan modified electrode. Microchem J 116:261-268. doi:10.1016/j.microc.2014.05.007

12. Hudari FF, Duarte EH, Pereira AC et al (2013) Voltammetric method optimized by multi-response assays for the simultaneous measurements of uric acid and acetaminophen in urine in the presence of surfactant using MWCNT paste electrode. J Electroanal Chem 696:52-58. doi:10.1016/j.jelechem.2013.01.033

13. Regina dos Santos Ruy M, Carneiro Figueira E, Del Pilar Taboada Sotomayor M (2014) Electroanalytical determination of bumetanide employing a biomimetic sensor for detection of doping in sports. Anal Methods 6:5792-5798. doi:10.1039/C4AY00255E

14. Liu Y, Dong X, Chen P (2012) Biological and chemical sensors based on graphene materials. Chem Soc Rev 41:2283-2307. doi: $10.1039 / \mathrm{c} 1 \mathrm{cs} 15270 \mathrm{j}$

15. $\mathrm{Xu} \mathrm{Y,} \mathrm{Gao} \mathrm{H,} \mathrm{Li} \mathrm{M} \mathrm{et} \mathrm{al} \mathrm{(2011)} \mathrm{Electronic} \mathrm{transport} \mathrm{in} \mathrm{monolayer}$ graphene with extreme physical deformation: ab initio density functional calculation. Nanotechnology 22:365202. doi:10.1088/09574484/22/36/365202

16. Zeng Y, Zhou Y, Zhou T, Shi G (2014) A novel composite of reduced graphene oxide and molecularly imprinted polymer for electrochemical sensing 4-nitrophenol. Electrochim Acta 130: 504-511. doi:10.1016/j.electacta.2014.02.130

17. Chen L, Tang Y, Wang K et al (2011) Direct electrodeposition of reduced graphene oxide on glassy carbon electrode and its electrochemical application. Electrochem Commun 13:133-137. doi:10. 1016/j.elecom.2010.11.033

18. Ping J, Wang Y, Fan K et al (2011) Direct electrochemical reduction of graphene oxide on ionic liquid doped screen-printed electrode and its electrochemical biosensing application. Biosens Bioelectron 28:204-209. doi:10.1016/j.bios.2011.07.018

19. Hilder M, Winther-Jensen B, Li D et al (2011) Direct electrodeposition of graphene from aqueous suspensions. Phys Chem Chem Phys 13:9187-9193. doi:10.1039/c1cp20173e

20. Hudari FF, da Silva BF, Pividori MI, Zanoni MVB (2016) Voltammetric sensor based on magnetic particles modified composite electrode for determination of triamterene in biological 
sample. J Solid State Electrochem 20:2491-2501. doi:10.1007/ s10008-015-3078-2

21. Wong A, Razzino CA, Silva TA, Fatibello-Filho O (2016) Squarewave voltammetric determination of clindamycin using a glassy carbon electrode modified with graphene oxide and gold nanoparticles within a crosslinked chitosan film. Sensors Actuators B Chem 231:183-193. doi:10.1016/j.snb.2016.03.014

22. Dong R, Liu L (2016) Preparation and properties of acrylic resin coating modified by functional graphene oxide. Appl Surf Sci 368: 378-387. doi:10.1016/j.apsusc.2016.01.275

23. Treossi E, Melucci M, Liscio A et al (2009) High-contrast visualization of graphene oxide on dye-sensitized glass, quartz, and silicon by fluorescence quenching. J Am Chem Soc 131:15576-15577. doi:10.1021/ja9055382

24. Deng K-Q, Zhou J, Li X-F (2013) Direct electrochemical reduction of graphene oxide and its application to determination of Ltryptophan and L-tyrosine. Colloids Surf B: Biointerfaces 101: 183-188. doi:10.1016/j.colsurfb.2012.06.007

25. Luo J, Zhang H, Jiang S et al (2012) Facile one-step electrochemical fabrication of a non-enzymatic glucose-selective glassy carbon electrode modified with copper nanoparticles and graphene. Microchim Acta 177:485-490. doi:10.1007/s00604-012-0795-4

26. Eda G, Fanchini G, Chhowalla M (2008) Large-area ultrathin films of reduced graphene oxide as a transparent and flexible electronic material. Nat Nanotechnol 3:270-274. doi:10.1038/nnano.2008.83

27. Stankovich S, Dikin DA, Piner RD et al (2007) Synthesis of graphene-based nanosheets via chemical reduction of exfoliated graphite oxide. Carbon N Y 45:1558-1565. doi:10.1016/j.carbon. 2007.02.034

28. Wang Y, Liu J, Liu L, Sun DD (2011) High-quality reduced graphene oxide-nanocrystalline platinum hybrid materials prepared by simultaneous co-reduction of graphene oxide and chloroplatinic acid. Nanoscale Res Lett 241:1-8. doi:10.1021/jp901437a

29. Xu T-Q, Zhang Q-L, Zheng J-N et al (2014) Simultaneous determination of dopamine and uric acid in the presence of ascorbic acid using Pt nanoparticles supported on reduced graphene oxide. Electrochim Acta 115:109-115. doi:10.1016/j.electacta.2013.10.147

30. Kucinskis G, Bajars G, Kleperis J (2013) Graphene in lithium ion battery cathode materials: a review. J Power Sources 240:66-79. doi:10.1016/j.jpowsour.2013.03.160

31. Bard AJ, Faulkner LR (2001) ELECTROCHEMICAL METHODS fundamentals and applications, 2nd edn. Wiley, New York

32. Sartori ER, Takeda HH, Fatibello-Filho O (2011) Glassy carbon electrode modified with functionalized carbon nanotubes within a poly(allylamine hydrochloride) film for the Voltammetric determination of sulfite in foods. Electroanalysis 23:2526-2533. doi:10. 1002/elan.201100122

33. Baizer MM, Lund H (1983) Organic electrochemistry-an introduction and a guide, 2nd edn. Marcel Dekker, New York

34. Legorburu MJ, Alonso RM, Jiménez RM (1993) Oxidative behavior of the sulfonamidic diuretic bumetanide at carbon paste electrode. Electroanalysis 5:333-338. doi:10.1002/elan.1140050411

35. Miller JCMJ (1988) Statistics for analytical chemistry, second. Ellis Horwood Limited, England 